Published in final edited form as:

Ann Neurol. 2017 June ; 81(6): 772-781. doi:10.1002/ana.24951.

\title{
Chemotherapy-Induced Peripheral Neuropathy: A Current Review
}

\author{
Nathan P. Staff ${ }^{1}$, Anna Grisold ${ }^{3}$, Wolfgang Grisold ${ }^{2}$, and Anthony J. Windebank ${ }^{1}$ \\ ${ }^{1}$ Department of Neurology, Mayo Clinic, Rochester, MN, USA \\ ${ }^{2}$ Ludwig Boltzmann Institute for Experimental und Clinical Traumatology, Vienna, Austria \\ ${ }^{3}$ Department of Neurology, Medical University of Vienna, Austria
}

\begin{abstract}
Chemotherapy-induced peripheral neuropathy (CIPN) is a common dose-limiting side effect experienced by patients receiving treatment for cancer. Approximately $30-40 \%$ of patients treated with neurotoxic chemotherapy will develop CIPN and there is considerable variability in its severity between patients. It is often sensory-predominant with pain and can lead to long-term morbidity in survivors. The prevalence and burden of CIPN late effects will likely increase as cancer survival rates continue to improve. In this review, we discuss the approach to peripheral neuropathy in patients with cancer and address the clinical phenotypes and pathomechanisms of specific neurotoxic chemotherapeutic agents.
\end{abstract}

\section{INTRODUCTION}

Peripheral neuropathies in cancer patients are most often due to neurotoxic chemotherapeutic agents, the so-called chemotherapy-induced peripheral neuropathy (CIPN); less frequently they occur as paraneoplastic, immune-mediated, or neoplastic neuropathies. CIPN is often a painful, dose-limiting side-effect that likely will increase in prevalence due to the progress made in cancer survival. CIPN is a common clinical problem; approximately $30-40 \%$ of patients receiving neurotoxic chemotherapy will suffer from this condition and it significantly increases the annual costs of healthcare ${ }^{1}$. Several classical chemotherapeutics (platinum, vinca alkaloids, taxanes) are well-established causes of CIPN. Newer agents also induce this side-effect despite different modes of more targeted cellular action. In this review, we will discuss the approach to peripheral neuropathy in the patient with cancer and provide an updated assessment of the neurotoxic mechanisms and clinical phenotypes of the specific chemotherapeutic agents.

Corresponding Author: Nathan P. Staff, M.D., Ph.D., Mayo Clinic, 200 First Street SW, Rochester, MN 55905, 507-284-8491 (phone), 507-284-4074 (fax), staff.nathan@mayo.edu.

AUTHOR CONTRIBUTIONS

All authors contributed to the study concept \& design, data acquisition \& analysis, and to drafting manuscript \& figures.

POTENTIAL CONFLICTS OF INTEREST

None 


\section{APPROACH TO PERIPHERAL NEUROPATHY IN PATIENT WITH CANCER}

When evaluating a patient with cancer that develops a neuropathy, determining whether they have CIPN requires an analysis of the administered drugs, the cumulative dosage, as well as the clinical characteristics and time course of the neuropathic symptoms. First, has the patient received a neurotoxic chemotherapeutic? The taxanes, platinum drugs, vinca alkaloids, thalidomide and bortezomib, all have a high likelihood of inducing CIPN. For some other drugs (such as cyclophosphamide or methotrexate) the likelihood is low with only single cases reported in the literature. Second, it is important to consider the route of drug administration. Methotrexate is rarely associated with neurological toxicity except when administered intrathecally ${ }^{2}$. Bortezomib neurotoxicity decreases with subcutaneous administration ${ }^{3}$. Third, has the patient received a drug dose commensurate with developing CIPN? Symptoms of CIPN typically begin during the first two months of treatment, progress while chemotherapy continues, and then stabilize soon after treatment is completed. While most CIPN occurs in a dose dependent fashion, other drug-specific features may be present such as the acute neurotoxicity of paclitaxel and oxaliplatin, or the worsening of neuropathy after discontinuation of cisplatin (coasting). It would be unexpected for CIPN to appear weeks or months after the last dose of neurotoxic chemotherapy treatment. Table 1 shows a summary of most commonly used drugs, and also estimates a cumulative dose associated with neuropathy for each drug when available.

Prior to making the diagnosis of CIPN in patients with cancer, it is important to consider other causes of neuropathy. Metabolic and endocrine-related neuropathies are rarely causes of acquired neuropathy in patients with cancer. Patients with diabetes mellitus may be at greater risk of developing CIPN ${ }^{\text {ref } 23}$. Paraneoplastic neuropathies usually occur at the onset of the cancer, but may rarely occur during treatment as in the dysimmune neuropathies of lymphomatous disorders ${ }^{4,5}$. Direct neoplastic infiltration may occur in neurolymphomatosis ${ }^{6-9}$, leukemia , and rarely carcinoma ${ }^{10}$, and may mimic chronic inflammatory demyelinating polyradiculoneuropathy (CIDP $)^{8,11}$. Paraproteinemias are associated with several different types of neuropathy ${ }^{12,13}$. Furthermore drug treatment of Waldenström's disease and multiple myeloma may involve the use of CIPN-causing medications (proteasome inhibitors, thalidomide, and related analogues), which can further complicate the determination of the etiology of the neuropathy. Bone marrow transplantation resulting in graft versus host disease can be associated with neuropathies such as GuillainBarre Syndrome (GBS) and CIDP ${ }^{14}$. In chronic settings other autoimmune neuropathies may be seen ${ }^{15-17}$. Finally, one must consider amyloid deposition in peripheral nerves occurring in paraproteinemic neuropathies, multiple myeloma (MM), and Waldenström's disease ${ }^{18,19}$.

\section{DRUG-SPECIFIC CLINICAL PRESENTATIONS AND NEUROTOXICITY IN CIPN}

CIPN is primarily caused by neurotoxic effects on neurons. Sensory symptoms tend to be greater than motor or autonomic. Neuropathy may be based on anatomic changes (e.g. distal axonal degeneration) or on physiological changes. Neuropathic pain is likely augmented by 
a combination of peripheral nerve hyperexcitability (via altered bioenergetics and ion channel expression) and central sensitization. The contribution of non-neuronal cells, such as Schwann cells to CIPN is not fully elucidated.

In most patients CIPN develops in a dose-dependent fashion after several cycles of neurotoxic chemotherapy administration and is typically dependent on the administered dose. Exceptions are the newer biological agents that induce a more idiosyncratic response as discussed below. Development of CIPN is an indication for dose reduction or discontinuation of the relevant chemotherapy agent. Discontinuation may hamper cancer treatment. Oncologists frequently weigh the risks of quality of life impairments from CIPN and benefits of possible cancer remissions or cures. When considering these options, it is important to note that conventional electrophysiology often does not mirror the patient`s symptoms and is difficult to use to monitor therapy. Furthermore, the Common Terminology Criteria for Adverse Events ${ }^{20}$, which is used in most cancer clinical trials, is not a sensitive instrument for measuring neuropathy. Methodologies to assess CIPN in clinical trials have therefore been developed to provide improved evaluation tools and patient reported outcomes. The EORTC QLQ-CIPN20 is a 20-item quality of life questionnaire that quantifies symptoms and impairments of sensory, motor, and autonomic neuropathy and has been used in large oncology clinical trials ${ }^{21}$. A more recent methodology, the CIPN-R-ODS, was developed with Rasch analysis to build overall disability scales that provide a linear measurement of CIPN-related disability and will likely be utilized in future CIPN clinical trials $^{22}$. Ideally, future CIPN clinical trial outcomes will also incorporate quantitative neurological exams and neurophysiology, such as those present in the Total Neuropathy Score clinical version (TNSc) ${ }^{23}$. Notably, the TNSc was recently subjected to Rasch analysis in patients with $\mathrm{CIPN}^{24}$; however, future validation studies will be required.

The majority of signs and symptoms due to CIPN arise from damage to dorsal root ganglion neurons or their axons, leading to acral pain, sensory loss and sometimes sensory ataxia. Motor, autonomic, and cranial nerve symptoms also may occur, but are less common. Most CIPN represents axonal damage in the form of a dying back neuropathy. There are however important exceptions. The widely used platinum compounds (carboplatin, cisplatin and oxaliplatin) cause a sensory neuronopathy. This selective vulnerability likely relates to the permeability of the blood-nerve barrier at the level of the dorsal root ganglion. For the neurologist trying to establish a causal relationship between chemotherapy treatment and development of neuropathy, the variability of presenting signs and symptoms in CIPN must be taken into consideration. Neurophysiology may also be helpful in this regard, providing the neurologist with data to distinguish between sensory neuronopathy, length-dependent sensorimotor neuropathy, or small fiber neuropathies. The clinical characteristics for the different medication classes are separately reviewed below.

\section{Platinum compounds}

The parent compound, cisplatin, has been in widespread use for forty years. It commonly causes ototoxicity with hearing loss and tinnitus, sensory neuropathy, nephropathy and myelosuppression. The latter two adverse events are manageable by pre-hydration of patients with normal saline or bone marrow stimulating agents (erythropoietin and G-CSF). 
The neuropathy and ototoxicity are only preventable with dose reduction or cessation of drug. Significant, dose-related moderate or severe hearing loss (20\%) and tinnitus (40\%) are reported in patients treated with cisplatin. It is often permanent ${ }^{25}$. Since both CIPN and hearing loss are dose-related, they occur concurrently in many patients but there is not a clear mechanistic or risk-based relationship between these effects. All of the platinum agents in routine use cause long-term peripheral sensory damage, much of which is due to neuronopathy ${ }^{26}$. This occurs in 30-40\% of patients treated with oxaliplatin and cisplatin and in the same proportion of patients treated with the commonly used combination of paclitaxel and carboplatin ${ }^{27}$. Of the platinum compounds cisplatin seems to be most frequently involved in peripheral neurotoxicity ${ }^{28}$. Carboplatin is considered as less neurotoxic than cisplatin $^{29}$. Treatment schedules ${ }^{30}$ and formulations ${ }^{31}$ can influence toxicity. In addition to the chronic neurotoxicities observed in all platinum-based compounds ${ }^{32}$, oxaliplatin is frequently associated with transient acute effects. Oxaliplatin acute neuropathic pain typically involves cold-induced dysesthesia that are most severe in the hands, face, and oral cavity. Cold wind on the face or cold drinks may induce intense pain. The symptoms typically begin with the second or third cycle of treatment and last for 2-4 days after drug infusion.

An important characteristic of platinum-based CIPN is the so-called "coasting" phenomenon. This refers to the observation that CIPN from platinum-based (especially cisplatin and oxaliplatin) agents may worsen for several months following the discontinuation of therapy. Coasting is disturbing for both the patient and the physician, who are expecting stabilization or improvement of neuropathic symptoms after the chemotherapy is stopped.

Much of the basic research into platinum-based CIPN pathomechanisms has focused on neurotoxic damage to dorsal root ganglion sensory neurons (Figure 1). Platinum-based compounds (cisplatin, oxaliplatin, carboplatin and analogs) damage dorsal root ganglia neurons by forming adducts with nuclear and mitochondrial DNA. Animal studies have shown that this leads to neuronal apoptosis due to aberrant entry into the cell cycle ${ }^{33,34}$, which corresponds to the clinical pattern of a neuronopathy. There is also direct damage to mitochondria due to impairment of mitochondrial DNA transcription, which has been theorized to underlie "coasting"35. Platinum adducts with nuclear DNA are repaired by nucleotide excision repair. This DNA repair process is not present in mitochondria. The accumulated and unrepaired Pt-DNA adducts in mitochondria may then lead to gradual attrition of intrinsic mitochondrial proteins due to failure of transcription after cessation of drug therapy. The acute symptoms of cold-induced dysesthesia in the hands and mouth from oxaliplatin are likely due to its effect on voltage-gated sodium channel kinetics ${ }^{36,37}$. This acute neurotoxicity is temporally independent of cumulative sensory toxicity but there is a correlation between the severity of dysesthesiae and the likelihood of developing the fixed sensory neuropathy ${ }^{38}$.

\section{Anti-microtubule Agents}

Taxanes-Taxanes (paclitaxel, docetaxel, cabaliztaxel) are widely used in oncology, and typically cause a dose-dependent, painful, length-dependent, sensory neuropathy due to 
dying back axonopathy. It may be partially reversible after treatment is discontinued. Of note, cabaliztaxel appears to have less cumulative toxicity ${ }^{39}$, but can cause dysgeusia ${ }^{40}$. Additionally, an acute, transient pain syndrome occurs in over half of patients treated with paclitaxel. It is characterized primarily by aching musculoskeletal pain ${ }^{41}$. This syndrome is not clearly due to nerve damage; however, it shares many clinical features with CIPN and may correlate with the development of paclitaxel-induced CIPN ${ }^{42}$.

Taxanes stabilize the dynamic assembly of polymer microtubule subunits. While they are thought to primarily exert their cancer-killing effects via disruption of microtubule-mediated cell division, it is less clear how they cause CIPN. Microtubules serve as the track for axonal transport, and taxanes interrupt this in vitro, which may lead to neuropathy ${ }^{43}$ (Figure 1). Other data demonstrate damage to mitochondria that may underlie a metabolic axonal failure in CIPN 44,45 . An intriguing novel study using the zebra fish model suggested that paclitaxel-induced neuropathy may depend on interactions between skin nerve endings and epidermal basal keratinocytes through the matrix metalloproteinase MMP- $13^{46}$.

Vinca alkaloids-Vinca alkaloids are used for the primary treatment of hematological malignancies, and typically cause a length-dependent sensory neuropathy, often with some degree of motor involvement ${ }^{47-50}$. They may cause long-term, residual neuropathic, late effects, in particular in the pediatric and young adult population. In addition vascular effects such as Raynaud syndrome can appear ${ }^{51}$. Cranial nerve and autonomic dysfunction occur but are rare $^{52}$.

In contrast to the taxanes, vinca alkaloids destabilize microtubule formation; however, the resulting impact on axonal transport and mitochondria function in neurons appears similar ${ }^{53}$. Recent preclinical data point to SARM1 as playing a key role in axonal degeneration due to vincristine toxicity, a finding that is likely is generalizable to other causes of CIPN. SARM1 is a protein that promotes Wallerian degeneration. Genetic deletion of SARM1 prevents development of neuropathy in vincristine treated mice ${ }^{54}$.

New anti-microtubule agents-Over the past several years, new chemotherapy agents have come to market that also impact microtubule dynamics. Eribulin and ixabepilone are two drugs used to treat breast cancer and cause an axonal sensorimotor peripheral neuropathy ${ }^{55}$. These drugs bind to the same site and have the same effect on microtubule dynamics as the taxanes. A new pharmaceutical approach is the conjugation of a chemotherapy agent with tumor specific antibodies as used in brentuximab vedotin where an antibody to CD30 (present on lymphoma) is conjugated to a microtubule toxin (monomethyl auristatin E). Despite the targeting to lymphoma, brentuximab vedotin causes an off-target peripheral neuropathy in $30-50 \%$ of patients ${ }^{56}$. Ado-trastuzumab emtansine combines an antibody against HER2 (breast cancer) and emtansine, which inhibits assembly of microtubule polymers and is associated with a high frequency of peripheral neuropathy 57 .

\section{Proteasome Inhibitors}

Bortezomib exerts its anti-neoplastic actions by inhibiting proteasomes, the primary intracellular protein degradation machinery. Bortezomib causes a painful length-dependent small fiber predominant axonal sensory neuropathy ${ }^{58}$. It is a reversible distal axonopathy ${ }^{59}$. 
Recently it was discovered that subcutaneous delivery decreases the likelihood and severity of the neuropathy ${ }^{3}$. A small proportion of patients receiving bortezomib develop a severe polyradiculoneuropathy, which appears to be immune-mediated ${ }^{60-62}$. Newer generation proteasome inhibitors, carfilzomib and ixazomib, are reported to have a lower incidence of CIPN 63,64 .

Interestingly, despite the potential widespread cellular impact of proteasome inhibition, bortezomib appears to be neurotoxic due to interference with microtubule and mitochondrial function Bortezomib increases microtubule polymerization and mitochondrial exhibit decreased axonal transport and function in sensory neurons ${ }^{45,65,66}$. but the precise mechanism of how this occurs is unclear. Other mechanisms may also be important in bortezomib induced peripheral neuropathy, including nuclear accumulations of ubiquinated proteins and altered protein transcription in sensory ganglion neurons ${ }^{67,68}$.

\section{Thalidomide}

A sensory-predominant neuropathy develops with long term thalidomide treatment ${ }^{69}$, which is used in treatment of multiple myeloma ${ }^{70}$. The neurotoxicity was well-known when the drug was introduced as a sedative in the $1960 \mathrm{~s}^{71}$. Deficit persisted in $75 \%$ of patients in long term follow up in the older studies. Lenalidomide and pomalidomide are newer formulations, which appear to have less neurotoxicity ${ }^{72,73}$.

Thalidomide and its analogues are thought to cause neuropathy via its anti-angiogenic effects ${ }^{74}$, and it has been theorized that impaired angiogenesis may play a significant role in CIPN from other agents ${ }^{74,75}$.

\section{Immune check point inhibitors}

Although not directly neurotoxic, immune-mediated neuropathies occur in association with use of the newer classes of immune check point inhibitors, which are being used in the treatment of melanoma and increasingly other tumors. Ipilimumab and tremelimumab target the human cytotoxic T-lymphocyte-associated antigen 4 (CTLA-4), leading to activation of cytotoxic T lymphocyte attack on cancer cells. Pembrolizumab and nivolumab are novel immune enhancing monoclonal antibody treatments for cancer (metastatic melanoma, nonsmall cell lung cancer, glioma) that target the PD-1 receptor, which regulates cell death in immune cells. A variety of neurological side effects have been reported with these immune check point inhibitors, including peripheral and central nervous system disorders, some of which are life threatening ${ }^{76,77}$. The reported neuropathy cases often closely resemble acute or chronic inflammatory demyelinating neuropathies ${ }^{78}$ or vasculitic neuropathies ${ }^{79}$.

Although they are considered as rare, they may occur in up to $3 \%$ of patients ${ }^{76}$. Treatment of these side effects is discontinuation of the immune-enhancing chemotherapy and institution of immunotherapy (steroids and/or IVIG), which is reported to be beneficial in many patients.

\section{LATE EFFECTS OF CHEMOTHERAPY ON THE NERVOUS SYSTEM}

The major late effect of chemotherapy agents on the nervous system is the residua of CIPN, much of which persists as a chronic pain syndrome. Discussion of a new late effect is 
emerging in the oncology and cancer survivor environment. Long term cognitive impairments after chemotherapy are being described in animal models ${ }^{80}$ and in patients ${ }^{81}$. The mechanistic basis for this phenomenon, referred to as "chemobrain", is that chemotherapeutic agents may affect neurogenesis in the adult brain. Cranial irradiation would be expected to potentiate this effect. Although this field is of great interest to investigators and patients, there is little research available yet. As cancer survivorship increase, it will likely become an important area for study.

\section{TREATMENT AND PREVENTION OF CIPN}

Unfortunately, there are no preventative treatments for CIPN ${ }^{82,83}$. It is challenging to understand why drugs directed towards killing rapidly dividing cancer cells also target nondividing, post-mitotic neurons. Developing CIPN-preventing agents is complicated by the concern that any agent may also decrease the efficacy of the chemotherapeutic. Preventative strategies must depend on either separating the mechanism of neurotoxicity from the mechanism of cancer cytoxicity or identifying cell properties unique to neuronal cells (e.g. receptor sensitivity to neuronal growth factors). Despite intense research efforts, this mechanism-based approach has not brought an effective treatment forward.

A second approach would be to identify patient-specific risk factors that could then be used in planning chemotherapeutic strategies for each patient. It is likely that many factors impact CIPN susceptibility including dose, route of delivery, concomitant medications, age, preexisting neuropathy and the type of cancer. Diabetes was a significant risk factor for the development of CIPN in a large cohort study of lung cancer patients treated with platinum and taxane drugs ${ }^{27}$. Genetic factors may also be important. Patients with Charcot-MarieTooth (CMT) disease can have increased susceptibility and severity of CIPN, especially in the setting of CMT1A and vinca alkaloids ${ }^{84-87}$. In many families disease gene carriers are minimally or asymptomatic. Multiple recent studies have revealed genetic variants associated with neurotoxic susceptibility to paclitaxel ${ }^{88-98}$, vincristine ${ }^{99-101}$, platinum compounds ${ }^{102-105}$, bortezomib ${ }^{99}$, thalidomide ${ }^{101}$, and combinations ${ }^{27}$, 106 . These studies have used a variety of techniques, including candidate gene and pathway analysis focused on cellular mechanisms implicated in CIPN 27, 88, 90, 99, 101, 102, 104-107, CMT genes ${ }^{92}$, or more broad genome-wide association studies ${ }^{91,94,95,97,98,100}$. Associations with RNA ${ }^{96,99}$ and protein 108 expressions have not been studied as intensely. The increased susceptibilities in these studies were relatively small (range of hazard/odds ratios 1.08-5.75) and there have been challenges with reproducibility ${ }^{107,109,110}$, which may reflect population differences. Currently there are no genetic tests available that help predict CIPN in an individual patient. The rapid development of inexpensive genetic and epigenetic sequencing technologies, combined with increasingly powerful bioinformatics approaches, predict that these riskbased approaches will be successful in the future.

Another novel approach is to identify individual patient-specific mechanisms. Induced pluripotent stem (iPS) cells derived from patient fibroblasts may be used to generate specific neuron subtypes susceptible to CIPN such as dorsal root ganglion neurons ${ }^{111}$. These lines may then be used to predict susceptibility or therapeutic response of the individual patient or to model and study disease mechanisms, so-called disease in a dish ${ }^{112}$. 
For the present treatment of CIPN relies on reducing or discontinuing the offending agent when CIPN develops and treating the symptoms of neuropathic pain. The National Cancer Institute has sponsored 15 CIPN-directed clinical trials that studied its prevention (alpha lipoic acid, intravenous calcium/magnesium, vitamin E, acetyl-L-carnitine, or glutathione) and symptomatic treatment (nortriptyline, gabapentin, lamotrigine, amifostine, topical amitriptyline/ketamine, topical baclofen,/amitriptyline/ketamine, or duloxetine) ${ }^{83}$. Of these studies, only duloxetine was shown to help neuropathic pain in established CIPN ${ }^{113}$. Many other medications (gabapentin, topical preparations, etc.) are used in an off-label fashion. Novel electrostimulation techniques have shown early promise ${ }^{114}$ but benefits need to be confirmed in ongoing larger randomized and controlled trials.

\section{CONCLUSIONS}

With the advent of newer and more targeted chemotherapies, there was hope that CIPN would wane as a significant clinical problem. Unfortunately, many of the older agents that cause CIPN continue to be mainstays of cancer therapy. Furthermore, many novel agents also have CIPN as a dose-limiting side-effect, whether as a direct toxicity or secondary due to immune-mediated processes. With improved cancer treatments and longer survival, the late effects of CIPN continue to produce a significant burden of suffering for cancer survivors.

\section{Acknowledgments}

Dr. Staff acknowledges a grant from National Cancer Institute (K08 CA 169443) during the conduct of the study.

\section{BIBLIOGRAPHY}

1. Pike CT, Birnbaum HG, Muehlenbein CE, Pohl GM, Natale RB. Healthcare costs and workloss burden of patients with chemotherapy-associated peripheral neuropathy in breast, ovarian, head and neck, and nonsmall cell lung cancer. Chemother Res Pract. 2012; 2012:913848. [PubMed: 22482054]

2. Brugnoletti F, Morris EB, Laningham FH, et al. Recurrent intrathecal methotrexate induced neurotoxicity in an adolescent with acute lymphoblastic leukemia: Serial clinical and radiologic findings. Pediatr Blood Cancer. 2009 Feb; 52(2):293-5. [PubMed: 18831032]

3. Moreau P, Pylypenko H, Grosicki S, et al. Subcutaneous versus intravenous administration of bortezomib in patients with relapsed multiple myeloma: a randomised, phase 3, non-inferiority study. The Lancet Oncology. 2011 May; 12(5):431-40. [PubMed: 21507715]

4. Briani C, Vitaliani R, Grisold W, et al. Spectrum of paraneoplastic disease associated with lymphoma. Neurology. 2011 Feb 22; 76(8):705-10. [PubMed: 21339498]

5. Stubgen JP. Lymphoma-associated dysimmune polyneuropathies. J Neurol Sci. 2015 Aug 15; 355(1-2):25-36. [PubMed: 26070654]

6. Baehring JM, Batchelor TT. Diagnosis and management of neurolymphomatosis. Cancer journal (Sudbury, Mass. 2012 Sep-Oct;18(5):463-8.

7. Grisariu S, Avni B, Batchelor TT, et al. Neurolymphomatosis: an International Primary CNS Lymphoma Collaborative Group report. Blood. 2010 Jun 17; 115(24):5005-11. [PubMed: 20368468]

8. Grisold WGA, Marosi Ch, Meng S, Briani Ch. Neuropathies associated with lymphoma. NeuroOncology Practice. 2015; 2(4):167-178. 2015. 
9. Viala K1BA, Maisonobe T, Léger JM. Neuropathy in lymphoma: a relationship between the pattern of neuropathy, type of lymphoma and prognosis? J Neurol Neurosurg Psychiatry. 2008 Jul; 79(7): 778-82. Epub 2007 Oct 30. [PubMed: 17971432]

10. Baehring JM, Damek D, Martin EC, Betensky RA, Hochberg FH. Neurolymphomatosis. Neuro Oncol. 2003 Apr; 5(2):104-15. [PubMed: 12672282]

11. Tomita MKH, Kawagashira Y, et al. Clinicopathological features of neuropathy associated with lymphoma. Brain. 2013; 136(Pt 8):2563-2578. 2013. [PubMed: 23884813]

12. Bayat EKJ. Neurological complications in plasma cell dyscrasias. Handb Clin Neurol. 2012; 105:731-46. 2012. [PubMed: 22230530]

13. Kelly JJ1KD. Lymphoma and peripheral neuropathy: a clinical review. Muscle Nerve. 2005 Mar; 31(3):301-13. 2005. [PubMed: 15543550]

14. Amato AA, Barohn RJ, Sahenk Z, Tutschka PJ, Mendell JR. Polyneuropathy complicating bone marrow and solid organ transplantation. Neurology. 1993 Aug; 43(8):1513-8. [PubMed: 8394521]

15. Krouwer HG, Wijdicks EF. Neurologic complications of bone marrow transplantation. Neurol Clin. 2003 Feb; 21(1):319-52. [PubMed: 12690654]

16. Mathew RM, Rosenfeld MR. Neurologic Complications of Bone Marrow and Stem-cell Transplantation in Patients with Cancer. Current treatment options in neurology. $2007 \mathrm{Jul}$; 9(4): 308-14. [PubMed: 17580010]

17. Rodriguez TE. Neurologic complications of bone marrow transplantation. Handb Clin Neurol. 2014; 121:1295-304. [PubMed: 24365420]

18. Gertz MA. Immunoglobulin light chain amyloidosis: 2014 update on diagnosis, prognosis, and treatment. American journal of hematology. 2014 Dec; 89(12):1132-40. [PubMed: 25407896]

19. Shin SC, Robinson-Papp J. Amyloid neuropathies. The Mount Sinai journal of medicine, New York. 2012 Nov-Dec;79(6):733-48.

20. Common Terminology Criteria for Adverse Events (CTCAE) v4.0. 2016. Available from: https:// ctep.cancer.gov/protocoldevelopment/electronic_applications/ctc.htm

21. Pachman DR, Qin R, Seisler DK, et al. Clinical Course of Oxaliplatin-Induced Neuropathy: Results From the Randomized Phase III Trial N08CB (Alliance). J Clin Oncol. 2015 Oct 20; 33(30):3416-22. [PubMed: 26282635]

22. Binda D, Vanhoutte EK, Cavaletti G, et al. Rasch-built Overall Disability Scale for patients with chemotherapy-induced peripheral neuropathy (CIPN-R-ODS). Eur J Cancer. 2013 Sep; 49(13): 2910-8. [PubMed: 23668917]

23. Cavaletti G, Jann S, Pace A, et al. Multi-center assessment of the Total Neuropathy Score for chemotherapy-induced peripheral neurotoxicity. J Peripher Nerv Syst. 2006 Jun; 11(2):135-41. [PubMed: 16787511]

24. Binda D, Cavaletti G, Cornblath DR, Merkies IS, group CI-Ps. Rasch-Transformed Total Neuropathy Score clinical version (RT-TNSc((c)) ) in patients with chemotherapy-induced peripheral neuropathy. J Peripher Nerv Syst. 2015 Sep; 20(3):328-32. [PubMed: 26306547]

25. Frisina RD, Wheeler HE, Fossa SD, et al. Comprehensive Audiometric Analysis of Hearing Impairment and Tinnitus After Cisplatin-Based Chemotherapy in Survivors of Adult-Onset Cancer. Journal of clinical oncology : official journal of the American Society of Clinical Oncology. 2016 Aug 10; 34(23):2712-20. [PubMed: 27354478]

26. Krarup-Hansen A, Rietz B, Krarup C, Heydorn K, Rorth M, Schmalbruch H. Histology and platinum content of sensory ganglia and sural nerves in patients treated with cisplatin and carboplatin: an autopsy study. Neuropathol Appl Neurobiol. 1999 Feb; 25(1):29-40. [PubMed: 10194773]

27. Johnson C, Pankratz VS, Velazquez AI, et al. Candidate pathway-based genetic association study of platinum and platinum-taxane related toxicity in a cohort of primary lung cancer patients. J Neurol Sci. 2015 Feb 15; 349(1-2):124-8. [PubMed: 25586538]

28. Bentzen AG, Balteskard L, Wanderas EH, et al. Impaired health-related quality of life after chemoradiotherapy for anal cancer: late effects in a national cohort of 128 survivors. Acta Oncol. 2013 May; 52(4):736-44. [PubMed: 23438358]

29. Schmoll HJ, Harstrick A, Bokemeyer C, et al. Single-agent carboplatinum for advanced seminoma. A phase II study. Cancer. 1993 Jul 1; 72(1):237-43. [PubMed: 8508413] 
30. Vandenput I, Vergote I, Neven P, Amant F. Weekly paclitaxel-carboplatin regimen in patients with primary advanced or recurrent endometrial carcinoma. International journal of gynecological cancer : official journal of the International Gynecological Cancer Society. 2012 May; 22(4):61722. [PubMed: 22426408]

31. Pignata S, Scambia G, Ferrandina G, et al. Carboplatin plus paclitaxel versus carboplatin plus pegylated liposomal doxorubicin as first-line treatment for patients with ovarian cancer: the MITO-2 randomized phase III trial. J Clin Oncol. 2011 Sep 20; 29(27):3628-35. [PubMed: 21844495]

32. Shahriari-Ahmadi A, Fahimi A, Payandeh M, Sadeghi M. Prevalence of Oxaliplatin-induced Chronic Neuropathy and Influencing Factors in Patients with Colorectal Cancer in Iran. Asian Pacific journal of cancer prevention : APJCP. 2015; 16(17):7603-6. [PubMed: 26625769]

33. Gill JS, Windebank AJ. Cisplatin-induced apoptosis in rat dorsal root ganglion neurons is associated with attempted entry into the cell cycle. J Clin Invest. 1998 Jun 15; 101(12):2842-50. [PubMed: 9637718]

34. McDonald ES, Windebank AJ. Cisplatin-induced apoptosis of DRG neurons involves bax redistribution and cytochrome c release but not fas receptor signaling. Neurobiol Dis. 2002 Mar; 9(2):220-33. [PubMed: 11895373]

35. Podratz JL, Knight AM, Ta LE, et al. Cisplatin induced Mitochondrial DNA damage in dorsal root ganglion neurons. Neurobiol Dis. 2011 Mar; 41(3):661-8. [PubMed: 21145397]

36. Park SB, Lin CS, Krishnan AV, Goldstein D, Friedlander ML, Kiernan MC. Oxaliplatin-induced neurotoxicity: changes in axonal excitability precede development of neuropathy. Brain. 2009 Oct; 132(Pt 10):2712-23. [PubMed: 19745023]

37. Sittl R, Lampert A, Huth T, et al. Anticancer drug oxaliplatin induces acute cooling-aggravated neuropathy via sodium channel subtype $\mathrm{Na}(\mathrm{V}) 1.6$-resurgent and persistent current. Proc Natl Acad Sci U S A. 2012 Apr 24; 109(17):6704-9. [PubMed: 22493249]

38. Pachman DR, Qin R, Seisler DK, et al. Clinical course of oxaliplatin-induced neuropathy: results from the randomized phase III trial N08CB (Alliance). Journal of Clinical Oncology. 2015; 33(30):3416-22. [PubMed: 26282635]

39. Di Lorenzo G, Bracarda S, Gasparro D, et al. Lack of Cumulative Toxicity Associated With Cabazitaxel Use in Prostate Cancer. Medicine (Baltimore). 2016 Jan.95(2):e2299. [PubMed: 26765406]

40. Omlin A, Sartor O, Rothermundt C, et al. Analysis of Side Effect Profile of Alopecia, Nail Changes, Peripheral Neuropathy, and Dysgeusia in Prostate Cancer Patients Treated With Docetaxel and Cabazitaxel. Clinical genitourinary cancer. 2015 Aug; 13(4):e205-8. [PubMed: 25733056]

41. Loprinzi CL, Reeves BN, Dakhil SR, et al. Natural history of paclitaxel-associated acute pain syndrome: prospective cohort study NCCTG N08C1. Journal of clinical oncology : official journal of the American Society of Clinical Oncology. 2011 Apr 10; 29(11):1472-8. [PubMed: 21383290]

42. Reeves BN, Dakhil SR, Sloan JA, et al. Further data supporting that paclitaxel-associated acute pain syndrome is associated with development of peripheral neuropathy: North Central Cancer Treatment Group trial N08C1. Cancer. 2012 Oct 15; 118(20):5171-8. [PubMed: 22415454]

43. Komiya Y, Tashiro T. Effects of taxol on slow and fast axonal transport. Cell Motil Cytoskeleton. 1988; 11(3):151-6. [PubMed: 2463106]

44. Xiao WH, Zheng H, Bennett GJ. Characterization of oxaliplatin-induced chronic painful peripheral neuropathy in the rat and comparison with the neuropathy induced by paclitaxel. Neuroscience. 2012 Feb 17.203:194-206. [PubMed: 22200546]

45. Zheng H, Xiao WH, Bennett GJ. Mitotoxicity and bortezomib-induced chronic painful peripheral neuropathy. Exp Neurol. 2012 Dec; 238(2):225-34. [PubMed: 22947198]

46. Lisse TS, Middleton LJ, Pellegrini AD, et al. Paclitaxel-induced epithelial damage and ectopic MMP-13 expression promotes neurotoxicity in zebrafish. Proc Natl Acad Sci U S A. 2016 Apr 12; 113(15):E2189-98. [PubMed: 27035978]

47. Bokemeyer C, Berger CC, Kuczyk MA, Schmoll HJ. Evaluation of long-term toxicity after chemotherapy for testicular cancer. J Clin Oncol. 1996 Nov; 14(11):2923-32. [PubMed: 8918489] 
48. Jain P, Gulati S, Seth R, Bakhshi S, Toteja GS, Pandey RM. Vincristine-induced neuropathy in childhood ALL (acute lymphoblastic leukemia) survivors: prevalence and electrophysiological characteristics. J Child Neurol. 2014 Jul; 29(7):932-7. [PubMed: 23781018]

49. Lavoie Smith EM, Li L, Chiang C, et al. Patterns and severity of vincristine-induced peripheral neuropathy in children with acute lymphoblastic leukemia. J Peripher Nerv Syst. 2015 Mar; 20(1): 37-46. [PubMed: 25977177]

50. Ramchandren S, Leonard M, Mody RJ, et al. Peripheral neuropathy in survivors of childhood acute lymphoblastic leukemia. J Peripher Nerv Syst. 2009 Sep; 14(3):184-9. [PubMed: 19909482]

51. Atas E, Korkmazer N, Artik HA, Babacan O, Kesik V. Raynaud's phenomenon in a child with medulloblastoma as a late effect of chemotherapy. Journal of cancer research and therapeutics. 2015 Jul-Sep;11(3):666.

52. Rosenthal S, Kaufman S. Vincristine neurotoxicity. Ann Intern Med. 1974 Jun; 80(6):733-7. [PubMed: 4364934]

53. Chan SY, Worth R, Ochs S. Block of axoplasmic transport in vitro by vinca alkaloids. J Neurobiol. 1980 May; 11(3):251-64. [PubMed: 6156229]

54. Geisler S, Doan RA, Strickland A, Huang X, Milbrandt J, DiAntonio A. Prevention of vincristineinduced peripheral neuropathy by genetic deletion of SARM1 in mice. Brain. 2016 Dec; 139(Pt 12):3092-108. [PubMed: 27797810]

55. Carlson K, Ocean AJ. Peripheral neuropathy with microtubule-targeting agents: occurrence and management approach. Clinical breast cancer. 2011 Apr; 11(2):73-81. [PubMed: 21569993]

56. Gopal AK, Ramchandren R, O'Connor OA, et al. Safety and efficacy of brentuximab vedotin for Hodgkin lymphoma recurring after allogeneic stem cell transplantation. Blood. 2012 Jul 19; 120(3):560-8. [PubMed: 22510871]

57. Krop IE, Modi S, LoRusso PM, et al. Phase 1b/2a study of trastuzumab emtansine (T-DM1), paclitaxel, and pertuzumab in HER2-positive metastatic breast cancer. Breast Cancer Res. 2016 Mar 15.18(1):34. [PubMed: 26979312]

58. Chaudhry V, Cornblath DR, Polydefkis M, Ferguson A, Borrello I. Characteristics of bortezomiband thalidomide-induced peripheral neuropathy. J Peripher Nerv Syst. 2008 Dec; 13(4):275-82. [PubMed: 19192067]

59. Richardson PG, Briemberg H, Jagannath S, et al. Frequency, characteristics, and reversibility of peripheral neuropathy during treatment of advanced multiple myeloma with bortezomib. J Clin Oncol. 2006 Jul 1; 24(19):3113-20. [PubMed: 16754936]

60. Mauermann ML, Blumenreich MS, Dispenzieri A, Staff NP. A case of peripheral nerve microvasculitis associated with multiple myeloma and bortezomib treatment. Muscle Nerve. 2012 Dec; 46(6):970-7. [PubMed: 23225391]

61. Ravaglia S, Corso A, Piccolo G, et al. Immune-mediated neuropathies in myeloma patients treated with bortezomib. Clin Neurophysiol. 2008 Nov; 119(11):2507-12. [PubMed: 18829381]

62. Saifee TA, Elliott KJ, Rabin N, et al. Bortezomib-induced inflammatory neuropathy. J Peripher Nerv Syst. 2010 Dec; 15(4):366-8. [PubMed: 21199108]

63. Kumar SK, Berdeja JG, Niesvizky R, et al. Safety and tolerability of ixazomib, an oral proteasome inhibitor, in combination with lenalidomide and dexamethasone in patients with previously untreated multiple myeloma: an open-label phase 1/2 study. Lancet Oncol. 2014 Dec; 15(13): 1503-12. [PubMed: 25456369]

64. Stewart AK, Rajkumar SV, Dimopoulos MA, et al. Carfilzomib, lenalidomide, and dexamethasone for relapsed multiple myeloma. N Engl J Med. 2015 Jan 08; 372(2):142-52. [PubMed: 25482145]

65. Meregalli C, Chiorazzi A, Carozzi VA, et al. Evaluation of tubulin polymerization and chronic inhibition of proteasome as citotoxicity mechanisms in bortezomib-induced peripheral neuropathy. Cell Cycle. 2014; 13(4):612-21. [PubMed: 24335344]

66. Staff NP, Podratz JL, Grassner L, et al. Bortezomib alters microtubule polymerization and axonal transport in rat dorsal root ganglion neurons. Neurotoxicology. 2013 Dec.39:124-31. [PubMed: 24035926]

67. Casafont I, Berciano MT, Lafarga M. Bortezomib induces the formation of nuclear poly(A) RNA granules enriched in Sam68 and PABPN1 in sensory ganglia neurons. Neurotox Res. 2010 Feb; 17(2):167-78. [PubMed: 19609631] 
68. Palanca A, Casafont I, Berciano MT, Lafarga M. Proteasome inhibition induces DNA damage and reorganizes nuclear architecture and protein synthesis machinery in sensory ganglion neurons. Cell Mol Life Sci. 2014 May; 71(10):1961-75. [PubMed: 24061536]

69. Grover JK, Uppal G, Raina V. The adverse effects of thalidomide in relapsed and refractory patients of multiple myeloma. Ann Oncol. 2002 Oct; 13(10):1636-40. [PubMed: 12377654]

70. Morawska M, Grzasko N, Kostyra M, Wojciechowicz J, Hus M. Therapy-related peripheral neuropathy in multiple myeloma patients. Hematol Oncol. 2015 Dec; 33(4):113-9.

71. Fullerton PM, O'Sullivan DJ. Thalidomide neuropathy: a clinical electrophysiological, and histological follow-up study. J Neurol Neurosurg Psychiatry. 1968 Dec; 31(6):543-51. [PubMed: 4303800]

72. Briani C, Torre CD, Campagnolo M, et al. Lenalidomide in patients with chemotherapy-induced polyneuropathy and relapsed or refractory multiple myeloma: results from a single-centre prospective study. J Peripher Nerv Syst. 2013 Mar; 18(1):19-24. [PubMed: 23521639]

73. San Miguel J, Weisel K, Moreau P, et al. Pomalidomide plus low-dose dexamethasone versus highdose dexamethasone alone for patients with relapsed and refractory multiple myeloma (MM-003): a randomised, open-label, phase 3 trial. Lancet Oncol. 2013 Oct; 14(11):1055-66. [PubMed: 24007748]

74. Kirchmair R, Tietz AB, Panagiotou E, et al. Therapeutic angiogenesis inhibits or rescues chemotherapy-induced peripheral neuropathy: taxol- and thalidomide-induced injury of vasa nervorum is ameliorated by VEGF. Mol Ther. 2007 Jan; 15(1):69-75. [PubMed: 17164777]

75. Kirchmair R, Walter DH, Ii M, et al. Antiangiogenesis mediates cisplatin-induced peripheral neuropathy: attenuation or reversal by local vascular endothelial growth factor gene therapy without augmenting tumor growth. Circulation. 2005 May 24; 111(20):2662-70. [PubMed: 15897348]

76. Voskens CJ, Goldinger SM, Loquai C, et al. The price of tumor control: an analysis of rare side effects of anti-CTLA-4 therapy in metastatic melanoma from the ipilimumab network. PLoS One. 2013; 8(1):e53745. [PubMed: 23341990]

77. Zimmer L, Goldinger SM, Hofmann L, et al. Neurological, respiratory, musculoskeletal, cardiac and ocular side-effects of anti-PD-1 therapy. Eur J Cancer. 2016 Apr 12.

78. de Maleissye MF, Nicolas G, Saiag P. Pembrolizumab-Induced Demyelinating Polyradiculoneuropathy. N Engl J Med. 2016 Jul 21; 375(3):296-7. [PubMed: 27468083]

79. Aya F, Ruiz-Esquide V, Viladot M, et al. Vasculitic neuropathy induced by pembrolizumab. Ann Oncol. 2016 Nov 17.

80. Nokia MS, Anderson ML, Shors TJ. Chemotherapy disrupts learning, neurogenesis and theta activity in the adult brain. Eur J Neurosci. 2012 Dec; 36(11):3521-30. [PubMed: 23039863]

81. Holmes D. Trying to unravel the mysteries of chemobrain. Lancet Neurol. 2013 Jun; 12(6):533-4. [PubMed: 23602780]

82. Albers JW, Chaudhry V, Cavaletti G, Donehower RC. Interventions for preventing neuropathy caused by cisplatin and related compounds. Cochrane Database Syst Rev. 2014; 3:CD005228.

83. Majithia N, Temkin SM, Ruddy KJ, Beutler AS, Hershman DL, Loprinzi CL. National Cancer Institute-supported chemotherapy-induced peripheral neuropathy trials: outcomes and lessons. Support Care Cancer. 2016 Mar; 24(3):1439-47. [PubMed: 26686859]

84. Chaudhry V, Chaudhry M, Crawford TO, Simmons-O'Brien E, Griffin JW. Toxic neuropathy in patients with pre-existing neuropathy. Neurology. 2003 Jan 28; 60(2):337-40. [PubMed: 12552058]

85. Chauvenet AR, Shashi V, Selsky C, Morgan E, Kurtzberg J, Bell B. Vincristine-induced neuropathy as the initial presentation of charcot-marie-tooth disease in acute lymphoblastic leukemia: a Pediatric Oncology Group study. J Pediatr Hematol Oncol. 2003 Apr; 25(4):316-20. [PubMed: 12679647]

86. Martino MA, Miller E, Grendys EC Jr. The administration of chemotherapy in a patient with Charcot-Marie-Tooth and ovarian cancer. Gynecol Oncol. 2005 May; 97(2):710-2. [PubMed: 15863189] 
87. Nakamura T, Hashiguchi A, Suzuki S, Uozumi K, Tokunaga S, Takashima H. Vincristine exacerbates asymptomatic Charcot-Marie-tooth disease with a novel EGR2 mutation. Neurogenetics. 2012 Feb; 13(1):77-82. [PubMed: 22271166]

88. Abraham JE, Guo Q, Dorling L, et al. Replication of genetic polymorphisms reported to be associated with taxane-related sensory neuropathy in patients with early breast cancer treated with Paclitaxel. Clin Cancer Res. 2014 May 1; 20(9):2466-75. [PubMed: 24599932]

89. Apellaniz-Ruiz M, Lee MY, Sanchez-Barroso L, et al. Whole-exome sequencing reveals defective CYP3A4 variants predictive of paclitaxel dose-limiting neuropathy. Clin Cancer Res. 2015 Jan 15; 21(2):322-8. [PubMed: 25398452]

90. Azoulay D, Leibovici A, Sharoni R, et al. Association between Met-BDNF allele and vulnerability to paclitaxel-induced peripheral neuropathy. Breast Cancer Res Treat. 2015 Oct; 153(3):703-4. [PubMed: 26272744]

91. Baldwin RM, Owzar K, Zembutsu H, et al. A genome-wide association study identifies novel loci for paclitaxel-induced sensory peripheral neuropathy in CALGB 40101. Clinical cancer research : an official journal of the American Association for Cancer Research. 2012 Sep 15; 18(18):5099109. [PubMed: 22843789]

92. Beutler AS, Kulkarni AA, Kanwar R, et al. Sequencing of Charcot-Marie-Tooth disease genes in a toxic polyneuropathy. Ann Neurol. 2014 Nov; 76(5):727-37. [PubMed: 25164601]

93. Boora GK, Kulkarni AA, Kanwar R, et al. Association of the Charcot-Marie-Tooth disease gene ARHGEF10 with paclitaxel induced peripheral neuropathy in NCCTG N08CA (Alliance). J Neurol Sci. 2015 Oct 15; 357(1-2):35-40. [PubMed: 26143528]

94. Chhibber A, Mefford J, Stahl EA, et al. Polygenic inheritance of paclitaxel-induced sensory peripheral neuropathy driven by axon outgrowth gene sets in CALGB 40101 (Alliance). Pharmacogenomics J. 2014 Aug; 14(4):336-42. [PubMed: 24513692]

95. Leandro-Garcia LJ, Inglada-Perez L, Pita G, et al. Genome-wide association study identifies ephrin type A receptors implicated in paclitaxel induced peripheral sensory neuropathy. J Med Genet. 2013 Sep; 50(9):599-605. [PubMed: 23776197]

96. Leandro-Garcia LJ, Leskela S, Jara C, et al. Regulatory polymorphisms in beta-tubulin IIa are associated with paclitaxel-induced peripheral neuropathy. Clin Cancer Res. 2012 Aug 15; 18(16): 4441-8. [PubMed: 22718863]

97. Schneider BP, Li L, Radovich M, et al. Genome-Wide Association Studies for Taxane-Induced Peripheral Neuropathy in ECOG-5103 and ECOG-1199. Clin Cancer Res. 2015 Nov 15; 21(22): 5082-91. [PubMed: 26138065]

98. Wheeler HE, Gamazon ER, Wing C, et al. Integration of cell line and clinical trial genome-wide analyses supports a polygenic architecture of Paclitaxel-induced sensory peripheral neuropathy. Clin Cancer Res. 2013 Jan 15; 19(2):491-9. [PubMed: 23204130]

99. Broyl A, Corthals SL, Jongen JL, et al. Mechanisms of peripheral neuropathy associated with bortezomib and vincristine in patients with newly diagnosed multiple myeloma: a prospective analysis of data from the HOVON-65/GMMG-HD4 trial. Lancet Oncol. 2010 Nov; 11(11):105765. [PubMed: 20864405]

100. Diouf B, Crews KR, Lew G, et al. Association of an inherited genetic variant with vincristinerelated peripheral neuropathy in children with acute lymphoblastic leukemia. Jama. 2015 Feb 24; 313(8):815-23. [PubMed: 25710658]

101. Johnson DC, Corthals SL, Walker BA, et al. Genetic factors underlying the risk of thalidomiderelated neuropathy in patients with multiple myeloma. Journal of clinical oncology : official journal of the American Society of Clinical Oncology. 2011 Mar 1; 29(7):797-804. [PubMed: 21245421]

102. Argyriou AA, Cavaletti G, Antonacopoulou A, et al. Voltage-gated sodium channel polymorphisms play a pivotal role in the development of oxaliplatin-induced peripheral neurotoxicity: results from a prospective multicenter study. Cancer. 2013 Oct 1; 119(19):3570-7. [PubMed: 23821303]

103. Chen J, Yin J, Li X, et al. WISP1 polymorphisms contribute to platinum-based chemotherapy toxicity in lung cancer patients. Int J Mol Sci. 2014; 15(11):21011-27. [PubMed: 25405734] 
104. Custodio A, Moreno-Rubio J, Aparicio J, et al. Pharmacogenetic predictors of severe peripheral neuropathy in colon cancer patients treated with oxaliplatin-based adjuvant chemotherapy: a GEMCAD group study. Ann Oncol. 2014 Feb; 25(2):398-403. [PubMed: 24351404]

105. Lecomte T, Landi B, Beaune P, Laurent-Puig P, Loriot MA. Glutathione S-transferase P1 polymorphism (Ile105Val) predicts cumulative neuropathy in patients receiving oxaliplatin-based chemotherapy. Clinical cancer research : an official journal of the American Association for Cancer Research. 2006 May 15; 12(10):3050-6. [PubMed: 16707601]

106. McWhinney-Glass S, Winham SJ, Hertz DL, et al. Cumulative genetic risk predicts platinum/ taxane-induced neurotoxicity. Clin Cancer Res. 2013 Oct 15; 19(20):5769-76. [PubMed: 23963862]

107. Bergmann TK, Vach W, Feddersen S, et al. GWAS-based association between RWDD3 and TECTA variants and paclitaxel induced neuropathy could not be confirmed in Scandinavian ovarian cancer patients. Acta Oncol. 2013 May; 52(4):871-4. [PubMed: 22877241]

108. Chen EI, Crew KD, Trivedi M, et al. Identifying Predictors of Taxane-Induced Peripheral Neuropathy Using Mass Spectrometry-Based Proteomics Technology. PLoS One. 2015; 10(12):e0145816. [PubMed: 26710119]

109. Gutierrez-Camino A, Martin-Guerrero I, Lopez-Lopez E, et al. Lack of association of the CEP72 rs924607 TT genotype with vincristine-related peripheral neuropathy during the early phase of pediatric acute lymphoblastic leukemia treatment in a Spanish population. Pharmacogenet Genomics. 2015 Nov 25.

110. Peng Z, Wang Q, Gao J, et al. Association between GSTP1 Ile105Val polymorphism and oxaliplatin-induced neuropathy: a systematic review and meta-analysis. Cancer Chemother Pharmacol. 2013 Aug; 72(2):305-14. [PubMed: 23695028]

111. Chambers SM, Qi Y, Mica Y, et al. Combined small-molecule inhibition accelerates developmental timing and converts human pluripotent stem cells into nociceptors. Nat Biotechnol. 2012 Jul; 30(7):715-20. [PubMed: 22750882]

112. Avior Y, Sagi I, Benvenisty N. Pluripotent stem cells in disease modelling and drug discovery. Nat Rev Mol Cell Biol. 2016 Mar; 17(3):170-82. [PubMed: 26818440]

113. Smith EM, Pang H, Cirrincione C, et al. Effect of duloxetine on pain, function, and quality of life among patients with chemotherapy-induced painful peripheral neuropathy: a randomized clinical trial. Jama. 2013 Apr 3; 309(13):1359-67. [PubMed: 23549581]

114. Majithia N, Smith TJ, Coyne PJ, et al. Scrambler Therapy for the management of chronic pain. Support Care Cancer. 2016 Jun; 24(6):2807-14. [PubMed: 27041741] 


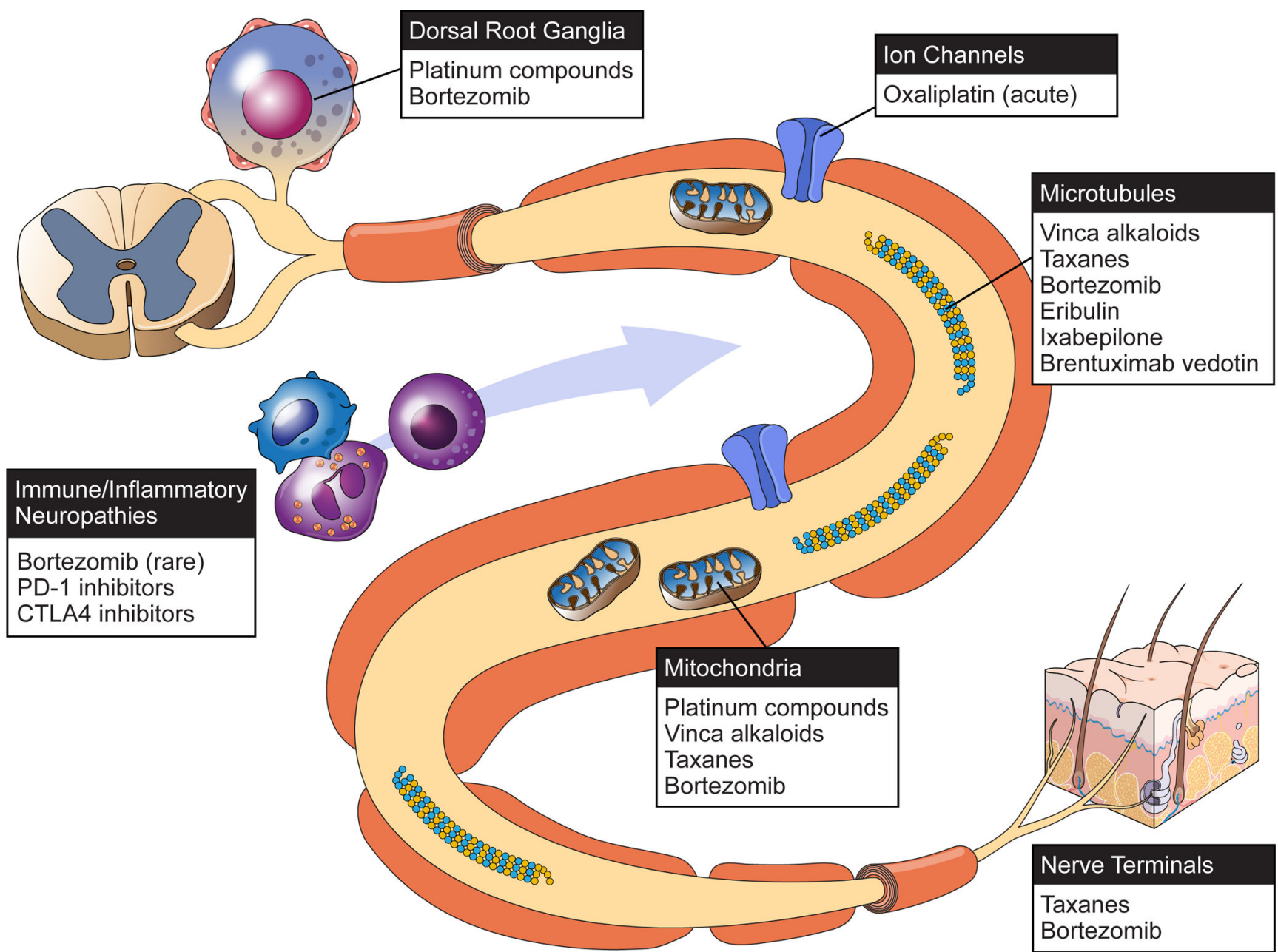

$3583048-1$

Figure 1.

Neurotoxic chemotherapeutic agents target multiple aspects of the sensory peripheral nerve. 


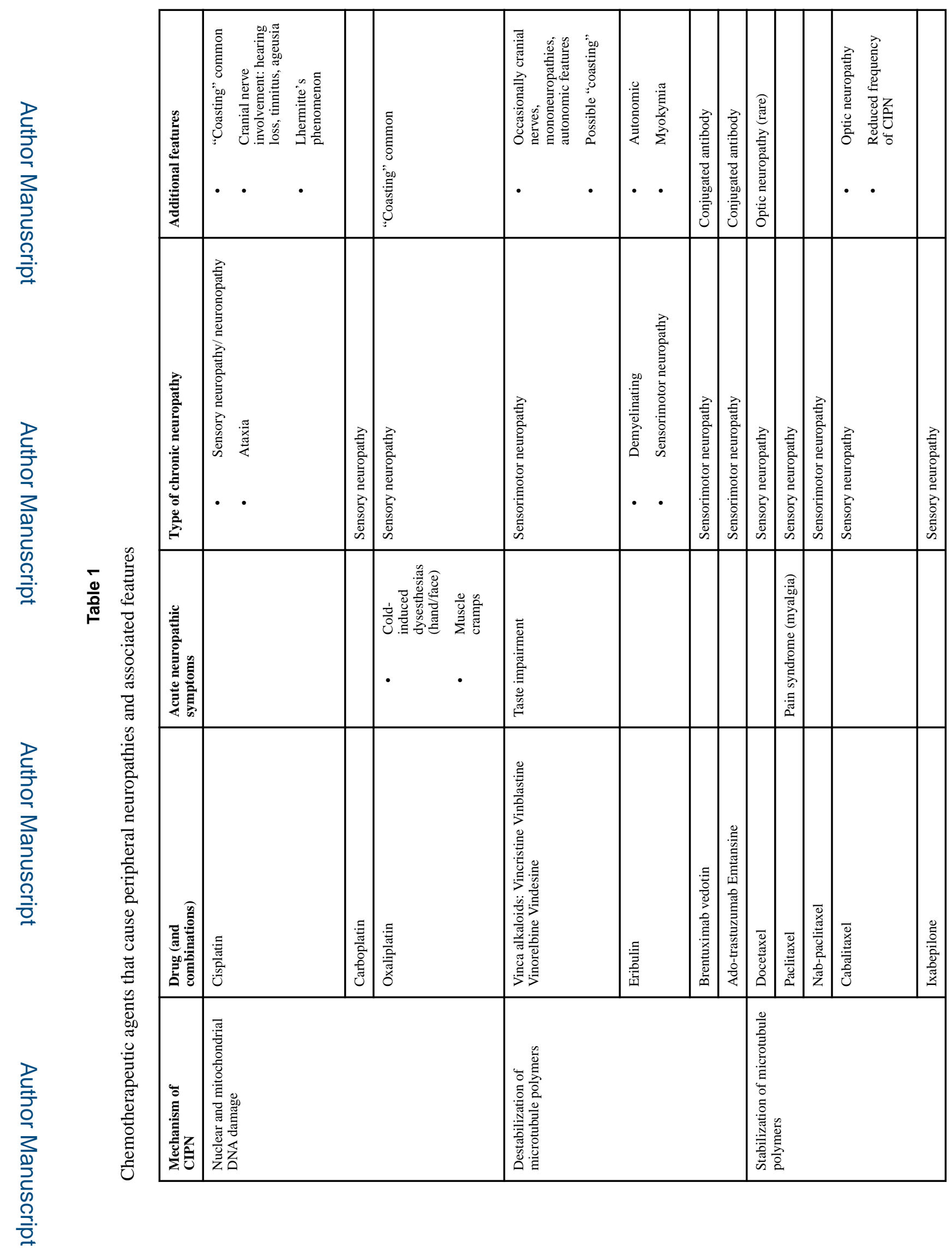

Ann Neurol. Author manuscript; available in PMC 2018 June 05. 


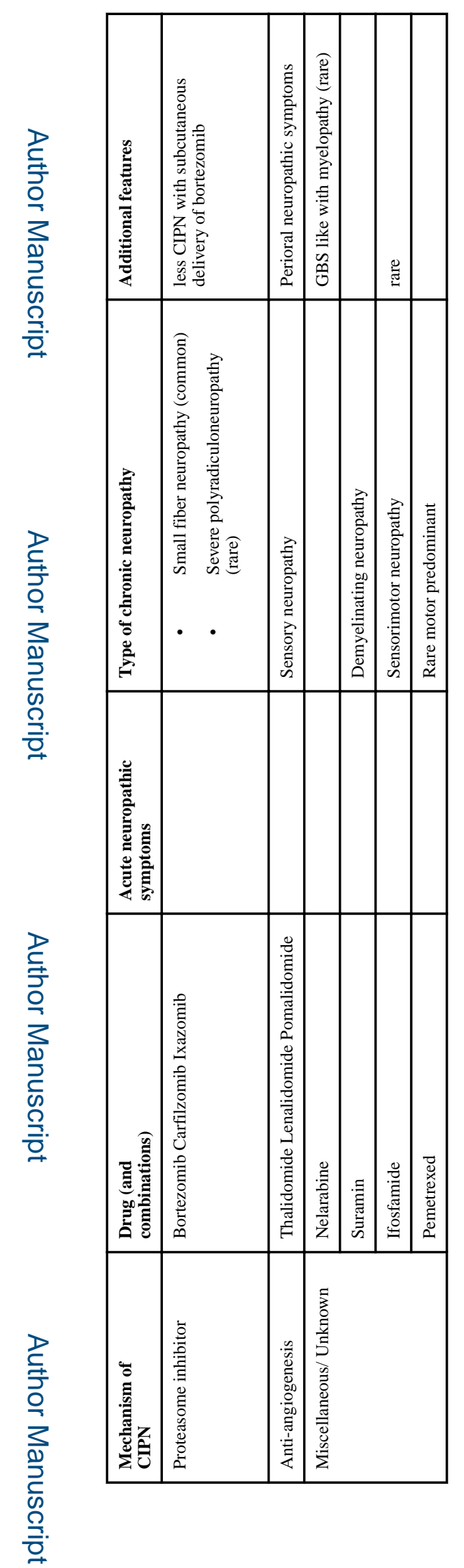

Ann Neurol. Author manuscript; available in PMC 2018 June 05. 